\title{
A socioeconomic analysis on tobacco cultivation in Kushtia District of Bangladesh
}

\author{
Md. Moyazzem Hossain“, Md. Mahabubur Rahman \\ Department of Statistics, IU, Kushtia, Bangladesh \\ Email address: \\ mmhrs.iustat@gmail.com (M. M. Hossain),sagorju151@gmail.com (M. M. Rahman)
}

\section{To cite this article:}

Md. Moyazzem Hossain, Md. Mahabubur Rahman. A Socioeconomic Analysis on Tobacco Cultivation in Kushtia District of Bangladesh. Social sciences. Vol. 2, No. 3, 2013, pp. 128-134. doi: 10.11648/j.ss.20130203.14

\begin{abstract}
Tobacco has been introduced since mid sixties of the last century into the fields where food crops were grown, and more widely after liberation in 1971 by the British American Tobacco Company in Teesta silt in Rangpur area. Bangladesh is one of the largest tobacco consuming countries in the world. Employment in tobacco farming accounts for less than $0.5 \%$ of agricultural employment in Bangladesh. Tobacco is grown throughout the country, with the largest tobacco growing areas including Rangpur, Kushtia, and Chittagong Hill. The purpose of this paper is to reveal some basic social and economical characteristics of tobacco growers. This paper investigates the impact of tobacco cultivation on environment and health. This paper also identifies the factors which are responsible for the profits of tobacco cultivation. The paper finds that tobacco cultivation has some negative effects on environment and health though it has some short term positive effects such as more profit. The paper also shows that the profits depends on so many factors some of them are cost on seed, fertilizer and other pesticides, labor, irrigation, production, price, etc.
\end{abstract}

Keywords: Tobacco, Regression, Bangladesh

\section{Introduction}

Tobacco has been introduced since mid sixties of the last century into the fields where food crops were grown, and more widely after liberation in 1971 by the British American Tobacco Company in Teesta silt in Rangpur area. Although Bangladesh Agricultural Research Institute (BARI) has conducted research and development activities of tobacco and abandoned in 1995, tobacco production has mainly been pushed by big multinational companies such as British American Tobacco Company through contract growers.

Bangladesh is one of the largest tobacco consuming countries in the world. Employment in tobacco farming accounts for less than $0.5 \%$ of agricultural employment in Bangladesh. Tobacco is grown throughout the country, with the largest tobacco growing areas including Rangpur, Kushtia, and Chittagong Hill. After many years as a net importer of tobacco leaf, acreage and yields rose beginning 1999, and Bangladesh has become a net exporter in recent years, exporting about one-third of the tobacco grown (Barakat A. et al., [1]).

The most important fact that needs to be recognized about tobacco is that it is a non-food crop -- it is not even a raw material for an industry that is necessary for the people of country. What it produces such as cigarette, bidi and other products are harmful and injurious to health. It is also not a 'cash crop' for farmers as the term is commonly understood. It is one of the very few crops in the world entering the world trade entirely as leaf. It is green from the planting time to the harvesting time, with no change in its green color. This is why the company uses the slogan "Sobujer Somaroho"-(the abundance of green) in order to deceive since such a green plant has absolutely no ecological value and economic value in the local or domestic market. It is a crop that has only one market, i.e. the tobacco companies and their agents and they are interested in the leaves which they grade for quality and therefore decide the price. It has no biomass that feeds back to the soil. The company purchases only the leaves that are grown. The rest of the plant remains on the ground and does more harm to the soil (Farida Akhter, [10]).

According to the official Agricultural Statistics [3] three varieties of tobacco--Jati, Motihari and Virginia-- are grown in different districts of Bangladesh. Jati and Motihari are mostly grown in Rangpur and Bandarban, while Virginia is mostly grown in Kushtia, Rangpur, Jessore and Dhaka. Other varieties such as Burley are also grown in limited quantities. In terms of land area covered by all three kinds of tobacco, Rangpur still remains highest with 40345 acres 
during 2008-09 followed by Kushtia 22241 and Bandarban 4678 acres of land. Besides tobacco is extending to Jessore, Jhenaidah, Nilphamari, Lalmonirhat and even in Manikganj and Tangail. Among the three varieties, Virginia is the most 'popular' variety for the companies. British American Tobacco (BAT) Company has introduced the Flue cured Virginia in 1967 on an experimental basis and by 1976 it started producing it commercially. Until 1971 Bangladesh had to import $95 \%$ of the total FCV consumed here. At present it is claimed that Bangladesh produces international standard Flue Cured Virginia (FCV) and the demand for Bangladesh tobacco is growing in the global market. This is perhaps due to restrictions in other countries on tobacco cultivation. Obviously, this is not good news for food production. The production of Virginia variety of tobacco during 2008-9 was 22,277 metric tons, while the other varieties, such as Jati were 8,437 metric tons and Motihari was 9,270 metric tons (BBS, [3]). The later two varieties are used for producing bidi - the local and cheaper version of cigarette. In the 2005-06 financial year, Bangladesh exported tobacco worth 95 crore 85 lakh 35 thousand (over 958 million) taka (Shafiq Rahman, [7]). This is not a big amount for an export commodity. Till 2007-08 the import of unmanufactured tobacco (Raw) was 1125 million Taka (Statistical Pocket Book, [2]).

Initially the grower of tobacco get some cash income but gradually have been incurring loss in terms of soil fertility, plant genetic resources, livestock and poultry and human health. According to UBINIG research, there are several reasons including cash earning, perceived high profit, guarantee of inputs and market and also the involvement of farmers through company card plays a coercive role for continuing tobacco cultivation. At the same time, lack of support for food production by the agriculture department discourages farmers to remain in food production. Tobacco companies can easily take advantage of the situation. Therefore, it is not true that the tobacco companies have involved the farmers in tobacco production only by motivation. The attractions that draw farmers to tobacco production are lump-sum cash income at a time, input and credit advance from the companies and ensured market through procurement of tobacco leaves by the companies. The most important effort of the companies is to bring the farmers into the company card system which entices the farmer for short or long time with tobacco production. Once a farmer is enrolled in the company card system it is very difficult to get out of tobacco production. The legal basis of the company card system is vague and deserves separate investigation that was not within the scope of the study (Farida Akhter, [10]).

For decades tobacco production has moved from one location to another, not due to the increased interest of farmers but rather due to the loss of soil fertility and destruction of sources of fuel wood in areas under production. This trend can be seen from government records 10 showing that tobacco leaves are produced in last ten years between 36,755 metric tons in $2000-01$ to 40,272 metric tons in 2008-9 with virtually no increase in land area (73,870 acres in 2000-1 to 73,811 acres in 2008-9). The unofficial statistics of tobacco cultivation far exceeds the government figures as the companies were moving from one district to the other, which are hardly updated in the national statistics; company moves mostly when they face decline in soil fertility and shortage of fuel wood for curing tobacco leaves. After Rangpur, the Teesta silt, tobacco production started at Kushtia in the fertile land of Gangetic Flood Plain and now to the Chittagong Hill Tracts mostly for the river Matamuhuri's fertile land and the trees in the hill forests. By 2005-06, Kushtia experienced again declining soil fertility and thereby low productivity and low quality of tobacco. The companies, already been aware of such possibilities, started moving to other districts. This time the movement was to the southern part of Bangladesh, particularly to the Chittagong Hill Tracts (CHT). Based on the availability of fuel wood tobacco production was started in Chittagong Hill Tracts (CHT), more specifically to Bandarban district since 1984. Initially tobacco was grown on 740 acres but it was increased on 4,750 acres in 2005-2006, an increase of 540\%. This was the same time, when Kushtia district started showing decline in soil fertility and no trees for firewood, except the ones such as Ipil Ipil, British American Tobacco Company provided in the name of saving the environment! However, tobacco cultivation is still extended within Kushtia district and in the adjoining districts. The rate of increase is $41 \%$. That means, the tobacco companies are concentrating more on the CHT where they can get the fertile land of the Matamuhuri River and can use the trees of the Hill Tracts (Farida Aktar, [10]).

In recent years 2007 to 2010 tobacco cultivation has again increased. It has increased indiscriminately and abruptly at the cost of intrusion in land suitable for production of food crops. In 2006-07 Tobacco production was 75860 acre and 2007-08 there was 71680 acre. In 2008-09 there was tobacco on 100863 acres. In 2009-10 tobacco cultivation was on $1,82,780$ acre. That means there was an increment of $141 \%$ in $2009-10$ as compared to 2006-07. It is surprising that there was no government policy to decide what crops are needed to be grown during these time and no steps taken to stop extension of tobacco. Companies, on the other hand, were very worried about the reduction of 4180 acre of land under tobacco in 2007-08 compared to 2006-07. It was observed in Kushtia that tobacco was grown on 46,517 acre in 2006-07. Next year (2007-08) there was tobacco on 32,791 acres. That means there was a reduction of $29 \%$ compared to the previous year. During this period, there was an increase of the cultivation of Maize in Kushtia. In 2008-09 tobacco cultivation increased in 35617 acres. Compared with 2007-08 there was an increase of 8.6\%. In Bandarban tobacco was grown on 4794 acres in 2006-07. In 2007-08 tobacco was grown on 6014 acre showing an increase of 25\%. But 2008-09 tobacco was grown on 5745 acres there was a reduction of acreage of tobacco in this year due to the efforts of the Army to protect hill Forest and restrict the cultivation of tobacco in boro rice field (Farida 
Aktar, [9]).

The Ministry of Agriculture, GoB is aware of the adverse impacts of the tobacco cultivation. One of the intelligence agencies of the government had investigated the adverse impacts of tobacco cultivation on behalf of the Ministry last year (2009). The agency had conducted through investigation in the south western region, including Kushtia district and adjoining areas. The Agriculture Minister, Begum Matia Chowdhury has approved the report on 15 April, 2010. It had been indicated in the report that the number of tobacco farmers increased alarmingly in Kushtia region. The tobacco producers were introduced at the cost of food crops including rice. Short and long term recommendations have been made in the report to change the situation. Withdrawal of subsidy on fertilizer for tobacco farming has been mentioned as an immediate measure. Fertilizer subsidy was withdrawn from the tobacco farmers based on the recommendation of that report. It was learnt that 18-20 thousand metric ton of fertilizer is used on for growing tobacco on 49,000 hectares in Kushtia region (Nijamul Haq Bipul, [14]).

It may be noted that profitability of tobacco cultivation is lucrative compared to some other crops. It ranks 15 among the major subsistence and cash crops in terms of financial profitability on the basis of full costs (see Zohir, [15]). However, most of the tobacco farmers are deprived off such profitability by denying a fair price of their 10 products through unscrupulous activities of the middlemen, moneylenders, and hostile BAT officials (see Chowdhury, [4]). Tobacco manufacturers claim that Bangladesh government receives sizeable amount of tax revenue from their products at different stages of processing. They, thus, argue that an increase in the rate of taxes would curtail consumption of the products, which, in turn, would cost government vital tax revenue from the sector and also propel the existing rising smuggling to a monumental scale. Government collects tax revenue from the tobacco manufacturers in various forms. Some of them include value-added tax, customs duty, and supplementary taxes and duties on domestically produced tobacco products as well as on imported ones. Jha and Chaloupka [5] reported that the impact of falling tobacco consumption would benefit the economy of Bangladesh. The extent of this benefit would be enormous; overall employment would increase by around 19 percent if all domestic tobacco consumption ceased as people switched to other goods that in turn generate more jobs that would more than compensate for the loss of tobacco employment.

There are several myths and a misgiving regarding the benefits of the production of tobacco leaf at the farm level and it's processing at the industry level in the economic development of a poor country such as Bangladesh. Tobacco companies argue that tobacco benefits Bangladesh's national economy in many ways. The main three of these include:

(i) generation of foreign exchange earnings through exports of unprocessed/semi processed tobacco products so as to help import capital goods for expediting industrialization;

(ii) creation of employment opportunities for the otherwise unemployed laborers through an ever expansion of the sector, and

(iii) contribution to the tax revenue to the government exchequer.

It is equally true that use of tobacco products in various forms is the single major cause several behavioral diseases such as lung cancer, cardiovascular diseases, etc. While manufacturers and growers may argue for its continuation as an economic sector the anti - tobacco groups may argue against for its harmful aspects. Thus, before taking any stance for or against the sector and the products it merits closely examination of the arguments with facts and figures.

Government policies and effort by non-government organizations to discourage smoking and other tobacco use began in the late 1980s. Some efforts have been made to inform and educate the public on the herm caused by tobacco use. Health warnings are required on cigarette packages, but they are very small and week and inaccessible to almost half of the population who are illiterate. The national radio and television stations stopped broadcasting advertisements for tobacco products in 1997. Regulation on tobacco cultivation is an urgent need for solving food crisis and for saving the environment and human health. However, since it is neither completely under agriculture, nor in industry, the regulation has not been very successful with enactment of the SMOKING AND TOBACCO PRODUCTS USAGE (CONTROL) ACT, 2005 by the Ministry of Health of the Government of Bangladesh. This law is enacted the with a view to controlling smoking, production of Tobacco, use, purchase, sale and advertisement. However, the bill also provides options about giving loan for food crops production in article 12 (see Farida Akhter, [9]).

Article 12: Granting of Loan for production of Alternative crops to tobacco products

(1) To discourage tobacco farmers from producing tobacco products and to encourage them to produce alternative cash crops the Government shall provide loan on simple terms and the facility shall continue for the next five (5) years from the coming into force of this Act.

(2) For motivating in gradually discouraging the production and use of tobacco products and for the purpose of discouraging the establishment tobacco products industry, the Government will formulate necessary policy.

\section{Methodology}

This is a field study research which has been made on the basis of a survey. A well structured questionnaire has been developed after an intensive review of the literature and practical experience. The target population of the study is the tobacco growers of Kushtia in Bangladesh. The sample unit of this study is the individual farmer (tobacco grower). 
The sample size is 262 farmers consisting male and female. Non-probability convenience sampling procedure has been used to collect primary data. Research was conducted in one of the most tobacco growing areas: Kushtia (Daulatpur and Mirpur Upazilla). Data collection was conducted on June-July of 2012.

\section{Findings of the Study}

\subsection{Age Distribution of the Respondent}

From the Table 1, we observe that among 262 respondents on an average 66 percent of the respondent's age less than 45 years. It is also observed that 8 percent of the respondent has age less than 25 years and about 11 percent of the respondent has age more than 55 years.

Table 1. Age of the respondents.

\begin{tabular}{ccc}
\hline Age in Years & Frequency & Percent \\
\hline$<25$ & 21 & 8.0 \\
$25-35$ & 73 & 27.9 \\
$35-45$ & 80 & 30.5 \\
$45-55$ & 59 & 22.5 \\
$55+$ & 29 & 11.1 \\
Total & 262 & 100.0 \\
\hline
\end{tabular}

\subsection{Occupational Status of the Respondent}

From Figure 1, we may conclude that among the respondents most of the respondent i., e., 83 percents were Farmer and also we observe that students also involve in tobacco cultivation but there involvement is too poor. Business man and service holder also engaged in tobacco cultivation.

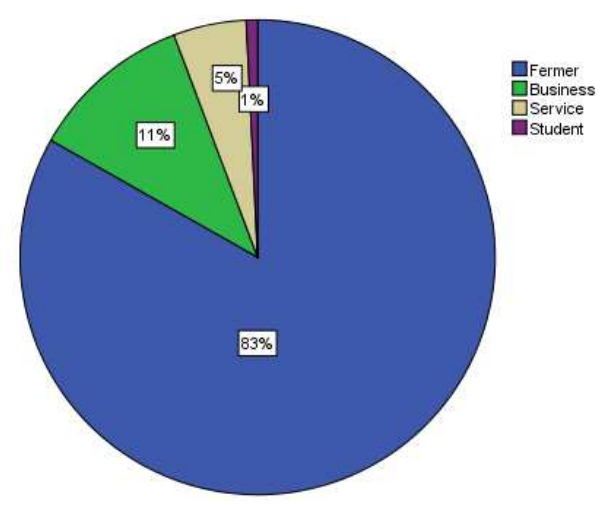

Figure 1. Occupation of the respondents

\subsection{Educational Status of the Respondent}

As individual becomes educated s/he knows the hazards of tobacco use. It is, therefore, expected that an inverse relationship would exist between the level of education and the tobacco cultivation. Educated people are more aware about the harmful effects of it. But this study shows that not only illiterate people but also educated people are related to grow tobacco. In this study around 47 percent of the respondents were reported as illiterate. Respondents with educational attainment up to SSC are about 45 percent. Around 8 percent of the respondent have educational qualification H.S.C. and above [Table 2]. This increase in the educational attainment may be attributed to the overall increase in literacy as well as the encouragement by the successive governments.

Table 2. Educational qualification of the respondent.

\begin{tabular}{ccc}
\hline Educational qualification & Frequency & Percent \\
\hline Illiterate & 123 & 46.9 \\
Five & 42 & 16.0 \\
Eight & 32 & 12.2 \\
S.S.C & 44 & 16.8 \\
H.S.C & 11 & 4.2 \\
B.Sc & 10 & 3.9 \\
Total & 262 & 100.0 \\
\hline
\end{tabular}

\subsection{Impacts of Tobacco Cultivation}

Tobacco smoking and other forms of tobacco use impose a large and growing public health burden globally and in Bangladesh. Globally, tobacco use currently causes 5.4 million premature deaths each year, and current trends predict that one billion people will die from tobacco use in the 21 st century (WHO, [16]). Smoke-free policies are limited to health care and educational (excluding university) facilities and do not cover bars, restaurants, government buildings, transport, indoor workplaces and other indoor public places. Tobacco advertising is banned on television and radio, in local magazines and newspapers, and on billboards, but is allowed at the point of sale. Tobacco company sponsorship of tournaments is banned, but promotional discounts and distribution of free samples are allowed. Health warnings are required on cigarette and bidi packages, but do not include graphic images, and no warnings are required on smokeless tobacco products. Tobacco excise taxes have increased over time, but tobacco products have become more affordable over time and significant tax increases have not been adopted to curb tobacco use. Currently, tobacco use causes nearly six million deaths per year worldwide - more than one in ten adult deaths. About $70 \%$ of current tobacco-attributable deaths occur in low and middle-income countries (Jha P. et al., [6]). Tobacco use is estimated to kill approximately 57,000 people in Bangladesh each year - about one in six of all deaths among people ages 30 years and older. 14 As in other countries, the majority of these deaths result from lung and other cancers, strokes, ischemic heart and other cardiovascular diseases, and respiratory diseases. Estimates indicate that there are about 1.2 million cases of lung cancer, cerebro-vascular disease, coronary artery diseases, chronic obstructive pulmonary disease and other tobacco-attributable illnesses in Bangladesh annually. Given the numerous diseases caused by tobacco use, the health care costs of treating these diseases are substantial. Estimates for 2004 indicate that the annual health care costs attributable to tobacco-related illnesses in Bangladesh were 50.9 billion taka (US\$ 856 million), including 5.8 billion taka (US\$ 98 
million) to treat the diseases caused by exposure to secondhand tobacco smoke (WHO, [17]).

Table 3. Opinions of the respondents about tobacco cultivation

\begin{tabular}{|c|c|c|}
\hline Opinions of the Respondents & Yes & No \\
\hline $\begin{array}{c}\text { Tobacco cultivation pollutes } \\
\text { environments }\end{array}$ & $163(62.2 \%)$ & $99(37.8 \%)$ \\
\hline $\begin{array}{l}\text { Tobacco cultivation decreases soil } \\
\text { fertility }\end{array}$ & $174(66.4 \%)$ & $88(33.6 \%)$ \\
\hline Tobacco cultivation is more profitable & $250(95.4 \%)$ & $12(4.6 \%)$ \\
\hline $\begin{array}{l}\text { Tobacco cultivation gives more money } \\
\text { at a time }\end{array}$ & $202(71.1 \%)$ & $60(22.9 \%)$ \\
\hline Tobacco cultivation is harmful for health & $197(75.2 \%)$ & $65(24.8 \%)$ \\
\hline $\begin{array}{c}\text { Tobacco cultivation needs a lot of } \\
\text { fertilizer }\end{array}$ & $175(66.8 \%)$ & $87(33.2 \%)$ \\
\hline $\begin{array}{l}\text { Tobacco cultivation is inspired by any } \\
\text { company }\end{array}$ & $241(92 \%)$ & $21(8 \%)$ \\
\hline $\begin{array}{c}\text { Company give loan for tobacco } \\
\text { cultivation }\end{array}$ & $161(61.5 \%)$ & $101(38.5 \%)$ \\
\hline
\end{tabular}

Tobacco as a 'crop' is harmful in many ways. For example, it has direct impact on soil depletion, pollution of soil and water from excessive use of chemical fertilizers, pesticide and irrigation water and worst of all is the damage to forest, homestead trees, road side trees etc. Tobacco is prone to many diseases therefore requires huge chemical inputs, upto 16 applications of pesticides including those which are banned for use such as Aldrin, Dieldrin, DDT (Md. R. A. Khan, [12]). There are studies which have shown the environmental, social and health impact of the tobacco cultivation but yet no strong step is taken by the government to stop such hazardous and aggressive crop. Its impact on food production is clearly understood because it occupies land of food crops for the entire year, it takes away the inputs needed for growing food crops and most importantly the specific areas growing tobacco become food deficit areas. The social impacts are also very much visible. In the families of tobacco growers, the stress situation hampers the family peace and happiness; children are deprived of going to school in tobacco harvesting and curing time (march-April) and also during firewood collection time in August-September. Men in all the families of the respondent get allured by cash income earned from tobacco. They see large amount of cash money which they receive after selling the leaves. But soon this money is spent for treatment of diseases that the family members suffer, paying for the debts, managing food costs as every food item has to be bought. At one point, they say that they do not have money anymore.

Since the start of tobacco cultivation and its gradual expansion without any regulation, the acreage and production of food crops started declining in the research areas. The trend is such that the production of vegetables has become negligible. The diversity of crops has been reduced with the introduction of tobacco. Only rice and some vegetables are grown in the kharif season. The farmers do not have any seed of food crops in their hand. The farmers have lost the tradition of maintaining seeds as food crops were not grown anymore. In case of urgent need for food production the farmers buy seed from the market mainly High yielding varieties (HYV) and hybrids. In this situation, a holistic approach is needed to invigorate the base of crop variability and diversity (Md. Mosharraf Uddin Mollah, [11]).

From Table 3 we can say that among 262 respondents 163 $(62.2 \%)$ says that tobacco cultivation pollutes the environment. About 66 percent tobacco grower says that soil fertility has been decreased by tobacco cultivation. Around 95 percent respondents reveal that tobacco cultivation is more profitable than cultivation other crops. This is a great threat to other crop production and continuing this one creates food crisis in our country in long run. By tobacco cultivation the tobacco growers get more money at a time from the company related to tobacco cultivation. It is observe that 92 percent of the respondent says that they are inspired to tobacco cultivation by any company situated in Kushtia. Tobacco cultivation requires large investments of cash causes farmers to borrow from moneylenders with high interest, leads to chronic indebtness. About 62 percent of the respondent says that they get loan for tobacco cultivation from a company. The major companies involved in tobacco leaf production as well as cigarette and bidi production in Kushtia areas are British American Tobacco (BAT) Company, Akij Tobacco, Abul Khair, Dhaka Tobacco, Nasir Tobacco. Around 67 percent tobacco grower says that they have to use more fertilizer in tobacco production and it affects the further production of other crops in the same land. Exposure to green leaves causes acute sickness making farmers often bedridden and causing vomiting, headache and breathing problems. In this study around 75 percent respondent says that they face some health related problem. They also say that the harvesting process of tobacco is so risky.

Though farmers face some problem to tobacco cultivation but it is more profitable. This sort term profit continues the tobacco cultivation though the long term effect is negative. The profits depends on so many factors some of them are cost on seed, fertilizer and other pesticides, labor, irrigation, etc.

Table 4. Model Summary

\begin{tabular}{cccccc}
\hline R & $\begin{array}{c}\text { R } \\
\text { Squar } \\
\text { e }\end{array}$ & $\begin{array}{c}\text { Adjusted } \\
\text { R Square }\end{array}$ & $\begin{array}{c}\text { Std. Error of } \\
\text { the Estimate }\end{array}$ & F & $\begin{array}{c}\mathbf{P} \\
\text { value }\end{array}$ \\
\hline 0.996 & 0.992 & 0.992 & 5083.246 & 4009.269 & .000 \\
\hline
\end{tabular}

From the Table 4 we may conclude that the fitted model is well and good since the value of $R^{2}$ is too high. Also the value of $F$ statistic shows that the model is fitted well. 
Table 5. Multiple Regression Results

\begin{tabular}{|c|c|c|c|c|}
\hline \multicolumn{5}{|c|}{ Coefficients } \\
\hline Variables & B & $\begin{array}{c}\text { Std. } \\
\text { Error }\end{array}$ & t & Sig. \\
\hline (Constant) & 983.622 & 2647.277 & .372 & .711 \\
\hline Amount of land $\left(X_{1}\right)$ & 867.485 & 133.953 & 6.476 & .000 \\
\hline Cost for seeds $\left(X_{2}\right)$ & 4.437 & 1.454 & 3.052 & .003 \\
\hline Cost for labor $\left(X_{3}\right)$ & 1.637 & .188 & 8.700 & .000 \\
\hline $\begin{array}{l}\text { Cost for irrigation } \\
\qquad\left(X_{4}\right)\end{array}$ & 3.330 & .282 & 11.822 & .000 \\
\hline $\begin{array}{l}\text { Cost for fertilizer } \\
\qquad\left(X_{5}\right)\end{array}$ & .629 & .288 & 2.185 & .030 \\
\hline $\begin{array}{c}\text { Cost for processing } \\
\left(X_{6}\right)\end{array}$ & 1.872 & .192 & 9.744 & .000 \\
\hline Production $\left(X_{7}\right)$ & 4.042 & .902 & 4.481 & .000 \\
\hline Price $\left(X_{8}\right)$ & 1.265 & .575 & 2.199 & .029 \\
\hline
\end{tabular}

From Table 5, we observed that all the coefficients of the independent variables included in the model are statistically significant at 5 percent level of significance. The profits on tobacco cultivation is forecasted by the following fitted regression equation

$$
\begin{gathered}
\text { Profit on Tobacco Cultivation }=983.622+867.485 X_{1} \\
+4.437 X_{2}+1.637 X_{3}+3.33 X_{4}+0.629 X_{5} \\
+1.872 X_{6}+4.042 X_{7}+1.265 X_{8}
\end{gathered}
$$

\section{Conclusion}

Tobacco has negative impacts on food security, soil water etc. its direct impact on health could not be documented. The health impacts of tobacco farming was becoming visible especially the farmers and their families continuously experience the occupational health impacts of growing tobacco. This paper finds that tobacco cultivation has some negative effects on environment and health though it has some short term positive effects such as more profit. The paper also shows that the profits depends on so many factors some of them are cost on seed, fertilizer and other pesticides, labor, irrigation, production, price, etc.

The direct users of tobacco, their family members including children and others, colleagues, in addition tobacco producers, processors, workers and all other peoples around are affected by the adverse impact of tobacco. The production of food crops has been reducing with time due to extension of tobacco production. A huge quantity of fuel wood is needed for curing of tobacco leaves, which releases poisonous smoke in the environment. Consequently trees are logged indiscriminately and the environment is polluted by the poisonous smoke.

Finally, it is recommended that a comprehensive policy on tobacco control in general and control tobacco cultivation in particular must be taken up by the government. As a part of global movement against usage of products, Bangladesh government as well as the groups working on tobacco control must incorporate the issues of harmful impact of tobacco cultivation on environment, food production and human health. It is not only the Ministry of Health that can take decision on controlling tobacco cultivation, but the Ministry of Finance, Ministry of Environment and Ministry of Agriculture must act together to regulate tobacco cultivation.

\section{References}

[1] Barkat A, Chowdhury AU, Nargis N, Rahman M, Kumar Pk A, Bashir S, Chaloupka FJ. , "The Economics of Tobacco and Tobacco Taxation in Bangladesh," Paris: International Union Against Tuberculosis and Lung Disease, 2012.

[2] Bangladesh Bureau of Statistics, "Statistical Pocket Book," Ministry of Planning, Dhaka, Bangladesh, Table 9.07, 2009.

[3] Bangladesh Bureau of Statistics, "Yearbook of Agricultural Statistics of Bangladesh 2009," Ministry of Planning, Dhaka, Bangladesh, 2010.

[4] Chowdhury, M. A. M., "A Socioeconomic Analysis of Tobacco Cultivation in Bangladesh: A Case Study of Meherpur, Rangpur and Rangunia," Journal of Business Studies, Vol. 1, 2001, pp. 48-65.

[5] Jha P., Chaloupka F. J., Moore J, Gajalakshmi V, Gupta P. C., Peck R, Asma S, Zatonski W., "Tobacco addiction," In: Jamison DT, Breman JG, et al. eds., Disease control priorities in developing countries, 2nd ed, Washington DC: International Bank for Reconstruction and Development/World Bank, 2006, pp. 869-885.

[6] Jha, P. and Frank J. Chaloupka, "Curbing the Epidemic: Governments and the Economics of Tobacco Control," World Bank, Washington D.C., 1999.

[7] Shafiq Rahman, "The thriving tobacco industry", PROBE NEWS MAGAZINE, Vol. 9, Issue 39, March 18-24, 2010. http://www.probenewsmagazine.com/index.php?index=2\&c ontentId $=4337$

[8] Sarkar and Haque, "Tobacco Agricultural Research in Bangladesh in the 20th Century," Bangladesh Agricultural Research Council, Dhaka, 2001.

[9] Farida Akhter, "Extensive cultivation of tobacco is creating food crisis in Bangladesh," UBINIG, 2010.

[10] Farida Akhter, "Tobacco cultivation is harmful," Daily New Age, Sunday, $\quad$ March 27, 2011. http://newagebd.com/newspaper1/archive_details.php?date= 2011-03-27\&nid=13131, Accessed 12/08/12

[11] Md. Mosharraf Uddin Mollah, Comparative Economics of producing alternative combinations of Rabi Crops by substituting Tobacco in Bangladesh, Consultant, UBINIG, 2010.

[12] Md. R. A. Khan, "Tobacco Control, Social, Environmental and Economic Perspective Choices for Bangladesh," Vol. 1, Department of Agricultural Marketing, 2007.

[13] Mohammad Yunus, "Craving for Nicotine: A Study on Tobacco Prevalence in Bangladesh," Bangladesh Institute of Development Studies, Dhaka, Bangladesh, 2001.

[14] Nijamul Haq Bipul, "Fertilizer subsidy was withdrawn from 
the tobacco farmers for upcoming season," The Jugantor, 17 April, 2010.

[15] Zohir, S., "Impact of Reforms in Agricultural Input Markets on Crop Sector Profitability in Bangladesh," mimeo., Bangladesh Institute of Development Studies, Dhaka, 2001.
[16] World Health Organization, "WHO Report on the Global Tobacco Epidemic," The MPOWER Package, Geneva: World Health Organization, 2008.

[17] World Health Organization, "Impact of Tobacco-related Illnesses in Bangladesh," New Delhi, India: World Health Organization, Regional Office for South-East Asia, 2007. 